\begin{tabular}{|c|c|}
\hline Title & A ntifouling properties of tough gels against barnacles in a long-term marine environment experiment \\
\hline Author(s) & $\begin{array}{l}\text { Murosaki, T.; Noguchi, T.; Hashimoto, K.; Kakugo, A .; Kurokawa, T.; Saito, J.; Chen, Y. M.; Furukawa, H.; Gong, J. } \\
\text { P. }\end{array}$ \\
\hline Citation & $\begin{array}{l}\text { Biofouling, 25(7), 657-666 } \\
\text { https://doi.org/10.1080/08927010903082628 }\end{array}$ \\
\hline Issue Date & $2009-10$ \\
\hline DOC URL & http:/hdl.handle.net/2115/43942 \\
\hline Rights & $\begin{array}{l}\text { This is an electronic version of an article published in Biofouling, 25(7), Oct. 2009, pp.657-666. Biofouling is available } \\
\text { online at: http:/www.informaworld.com/openurl?genre=article\&issn=1029-2454\&volume=25\& issue }=7 \& \text { spage }=657\end{array}$ \\
\hline Type & article (author version) \\
\hline File Information & Bf25-7_657-666.pdf \\
\hline
\end{tabular}

Instructions for use 


\section{Antifouling properties of tough gels against barnacles in long-term marine environment experiment}

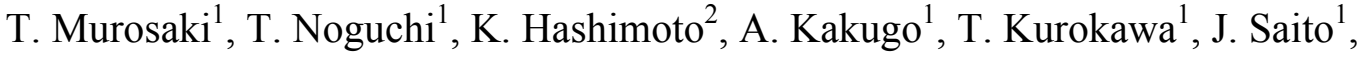

Y. M. Chen ${ }^{1}$, H. Furukawa ${ }^{1}$, J. P. Gong ${ }^{1, *}$

${ }^{1}$ Department of Biological Science, Graduate School of Sciences, Hokkaido University, Sapporo 060-0810, Japan; ${ }^{2}$ Hashimoto kogyou Ltd., Mihama 919-1123, Japan

*Corresponding author. Email: gong@sci.hokudai.ac.jp

Keywords: Polymer, gel, barnacle, biofouling, antifouling, marine environment 


\section{Introduction}

Marine fouling to submerged surfaces by macrofoulers is a serious pollution that causes economic and environment problems in various areas. Barnacles are one of the macrofoulers that adhere wall-to-wall to several submerged surfaces, such as fishnets, ship hulls, and cooling-water-intake channels of power plants. To inhibit the fouling by macrofoulers, several antifouling compounds have been developed. Tributyltin (TBT) is the most popular antifouling agent, and it exhibits a high antifouling activity. However, TBT is banned worldwide since 2008 due to its high endocrine-disruption effect (IMO 1999). Many effects have been done on development of new alternative antifouling materials to protect submerged surfaces. However, there are no suitable replacements currently available for TBT. (Chambers et al. 2006)

Recently, we reported that many synthetic polymer gels with various kinds of chemical structures have antifouling activities against barnacle cyprid larvae in vitro (Murosaki et al. 2009). They are neutral hydrogels: poly(acrylamide) (PAAm), poly(N,N'-dimethylacrylamide) (PDMAAm), PHEMA, and poly(2hydroxyethylacrylate) (PHEA) gels; positively charged hydrogels: poly(N,Ndimethylaminopropylacrylamide, methylchloride quarternary) (PDMAPAA-Q) and poly(N,N-dimethylaminoethylacrylate, methylchloride quarternary) (PDMAEA-Q) gels; negatively charged hydrogels: poly(sodium p-styrene sulfonate) (PNaSS), poly(2acrylamide-2-methyl-1-propanesulfonate) (PAMPS), and poly(2-acrylamide-2-methyl1-propanesulfonic sodium) (PNaAMPS); double network (DN) gels that consist of 2 interpenetrating polymer networks (Gong et al. 2003): PAMPS/PAAm DN gel and PAAc/PAAm DN gel; and physically crosslinked PVA gel. 
However, these researches on hydrogels were performed in laboratory, only on the initial settlement of acorn barnacles. A searching of literature also tells us that few researches on the antifouling of hydrogel have been performed in marine environment. M. J. Cowling et al. reported that poly (2-hydroxyethylmethacrylate) (PHEMA) gel inhibited the fouling of some algae and diatoms in the laboratory and also in the marine environment for 1 month (Cowling et al. 2000). Furthermore, no long term (longer than one month) experimental results have been reported. The main reason is because hydrogels are usually mechanically too weak to withstand the severe marine environment for a long time.

In this paper, we reported the antifouling properties of various kinds of hydrogels in marine environments. To perform long-term antifouling experiment, we need to overcome two main obstacles: one is the weak mechanical strength of the gel, the other is the method to fix the gel sample in marine environment. Three tests with different gel samples and fixation methods were performed in this work. In the first test, gel films (ca. several hundreds of $\mu \mathrm{m}$ in thickness) were coated on polyethylene (PE) plate. However, the antifouling properties of the gels could not be tested due to erosion of the gel film from the PE plate within a short period. In the second test, self-standing bulk gels were sandwiched between 2 stainless meshes with wire. Most hydrogels can only function in a marine environment for 2 months due to their mechanical weakness. The recently developed PAMPS/PAAm DN gel (Gong et al. 2003) and physically crosslinked PVA gels are considered to be tough enough to permit long term investigation of their antifouling properties in the marine environment. Thus, in the third method, these two mechanically strong gels were directly fixed with stainless frames without the stainless meshes. As the result, the tough DN and PVA gels showed no mechanical damage for 1 
year in the marine environment. Thus, the "antifouling" ability on the gel substrates was assessed, for the first time, over a period as long as one year. We found that the fouling on soft and wet gels was $1 / 10 \sim 1 / 5$ of that on the hard and dry PE control. The macrofouling on the PE substrate was mainly by barnacles while other sessile organisms were the main components of the fouling. Furthermore, we found that the morphology of the barnacle bottom surface depended on the substrate on which it settled.

Since hydrogels exhibit excellent antifouling activities without toxicity, they can be used as coating materials to produce inoffensive antifouling surfaces. Furthermore, hydrogels generally exhibit a fascinatingly low friction (Gong, 2006); therefore, they can be employed for submerged surfaces where low friction is required such as ship hulls and power plant cooling-water-intake channels. 


\section{Materials and methods}

\section{Reagents}

Poly (vinyl alcohol) $(\mathrm{PVA})(\mathrm{Mw}=95000)$ and $\kappa$-carrageenan were purchased from Wako Pure Chemicals (Osaka, Japan). Agarose was purchased from Sigma-Aldrich (USA). 2-Acrylamide-2-methylpropanesulfonic acid (AMPS) was courtesy of Toagosei (Tokyo, Japan). Acrylamide (AAm) (Junsei chemicals, Tokyo, Japan) was purified by recrystallization from chloroform. Acrylic acid (AAc) (Kanto Chemicals, Tokyo, Japan) were distilled at a reduced pressure. N,N'-methylenebis(acrylamide) (MBAA) (Tokyo Kasei Kogyo, Tokyo, Japan), a crosslinking agent, was purified by recrystallization from ethanol. 2-Oxoglutaric acid (Wako pure chemicals, Osaka, Japan), an initiator of free radical polymerization, was used as purchased.

\section{Sample preparation for field test}

(1) Physical, chemical, double network and triple network gels. Agarose and $\kappa-$ carrageenan gels were obtained by cooling $10 \mathrm{wt} \%$ hot solution of the corresponding polymers. PAAm, PAMPS, and PAAc gels were synthesized by radical polymerization. Monomer aqueous solution ( $1 \mathrm{~mol} / \mathrm{L}$ ) containing $4 \mathrm{~mol} \% \mathrm{MBAA}$ (as a crosslinker) and $0.1 \mathrm{~mol} \%$ 2-oxoglutaric acid (as initiator) in glass reaction cell was purged with argon gas to eliminate the inhibition effect of oxygen for polymerization. Each solution was irradiated with UV light (wavelength $365 \mathrm{~nm}$ ) for $10 \mathrm{~h}$ (Chen et al. 2005). PAMPS/PAAm DN, and PAAc/PAAm DN gels were synthesized by 2 steps sequential network formation technique (Gong et al. 2003). In the first step, PAMPS or PAAc gel (first network) was synthesized from a 1 mol/L monomer aqueous solution containing $4 \mathrm{~mol} \% \mathrm{MBAA}$ and $0.1 \mathrm{~mol} \%$ 2-oxoglutaric acid by radical polymerization 
as described above. The gel was immersed into $2 \mathrm{~mol} / \mathrm{L}$ AAm aqueous solution containing $0.1 \mathrm{~mol} \%$ 2-oxoglutaric acid for at least $1 \mathrm{~d}$ until reaching the equilibrium. After the swollen gel was taken out from AAm solution, the second network (PAAm) was subsequently polymerized in the presence of the first network gel (PAMPS or PAAc) under irradiation of UV light for $10 \mathrm{~h}$ between 2 plates of glass. PAMPS/PAAm/PAMPS TN, and PAAc/PAAm/PAAc TN gels were synthesized by UV irradiation after immersing the DN gels in a large amount of a third solution of $1 \mathrm{~mol} / \mathrm{L}$ AMPS or AAc in the presence of $0.1 \mathrm{~mol} \%$ MBAA and $0.1 \mathrm{~mol} \%$ 2-oxoglutaric acid.

The physically cross-linked PVA gel was prepared by a freezing and thawing method from a prescribed $10 \mathrm{wt} \%$ PVA aqueous solution. The solution was prepared by heating a mixture of PVA in the aqueous medium for $1 \mathrm{~h}$ at $\sim 90{ }^{\circ} \mathrm{C}$. After the heating step, the PVA solution was cast between glass plates. PVA gel was obtained by 7 cycles of freezing $\left(-40^{\circ} \mathrm{C}\right)$ and thawing $\left(25^{\circ} \mathrm{C}\right)$ (Kagata et al. 2002).

(2) Gel films. PAAm, PAAc, and PAMPS gel films (the thicknesses were several hundreds $\mu \mathrm{m})$ were prepared as follows. Benzophenone $(0.3 \mathrm{wt} \%)$ and vinyl acetate polymer $(1 \mathrm{wt} \%)$ were dissolved in acetone used as initiator solution. PE plates were immersed in the initiator solution for $10 \mathrm{~min}$, and then were dried in a desiccator to remove the acetone. A monomer ( $1 \mathrm{M})$ and MBAA (4 mol\%) were dissolved in purified water and bubbled with argon for $30 \mathrm{~min}$. The solution was then injected into a cell that consisted of a glass plate and a PE plate separated by a teflon tape of $200 \mu \mathrm{m}$ thickness. The cell was irradiated with a UV lamp $60 \mathrm{~cm}$ from the PE plate side for $2 \mathrm{~h}$ to polymerize the monomer. PAMPS/PAAm DN and PAAc/PAAm DN gels were 
synthesized using the above gel film on PE by the second polymerization protocol as described above.

\section{Experiment in the marine environment}

Three field experiments were conducted at Wakasa Bay, Fukui, Japan $\left(35^{\circ} 44^{\prime} \mathrm{N}\right.$ $\left.136^{\circ} 1^{\prime} \mathrm{E}\right)$. Experimental periods were between May 9, 2005, and October 13, 2005; between May 24, 2006, and October 10, 2006; and between May 10, 2007, and April 4, 2008, respectively, for the 3 experiments. 


\section{Results and discussion}

Field tests were carried out near the coast of Wakasa Bay, Fukui, Japan in summer (average water temperature, $23{ }^{\circ} \mathrm{C}$ ) since in winter (average water temperature $14{ }^{\circ} \mathrm{C}$ ) settlement of barnacles was observed to be less.

To perform the antifouling test in the marine environment, we first had to design a suitable method to fix the gel samples in the sea. Three methods were tested. In the first method, thin gels (ca. several hundreds of $\mu \mathrm{m}$ in thickness) (PAAm, PAAc, PAMPS, PAMPS/PAAm DN, and PAAc/PAAm DN) were coated on a $10 \times 10 \mathrm{~cm}^{2}$ polyethylene (PE) plate. The samples prepared in this way were fixed on a stainless frame (Figure 1a) and immersed in the sea at a depth of 5 or $8 \mathrm{~m}$ below the sea surface with nylon ropes from a raft. Uncoated PE plates were used as controls. However, the antifouling properties of the gels could not be tested due to erosion of the gel film from the PE plate in sea environment during the $139 \mathrm{~d}$ test period.

In the second method, self-standing bulk gels with thicknesses ranging between 0.5 and $2.0 \mathrm{~cm}$ were used. The $50-100 \mathrm{~cm}^{2}$ quadrangle gel samples were sandwiched between 2 stainless meshes with wire (Figure 1b). Agarose, $\kappa$-carrageenan, PAAm, PAMPS, PAAc, PAMPS/PAAm DN, PAAc/PAAm DN, PAMPS/PAAm/PAMPS triple network (TN), and PAAc/PAAm/PAAc TN gels were used. The PAAc and agarose gels were opaque; the PAAm, PAAc/PAAm DN, and PAAc/PAAm/PAAc TN gels were semitransparent; whereas the others were transparent. Polyvinyl chloride and teflon plates $\left(10 \times 10 \mathrm{~cm}^{2}\right)$ were also used as solid state-material controls. Test specimens were immersed in the sea at a depth of 5 or $8 \mathrm{~m}$ beneath the sea surface with nylon ropes from a raft. Table 1 shows the results obtained from the experiments with the hydrogels and plastic plates. All the gels exhibit antifouling activity; however, only 
the PAMPS/PAAm DN gel survived after $157 \mathrm{~d}$ in the marine environment. The other gels were damaged, probably due to abrasion with the sharp edges of the stainless meshes. Attachment of algae and ascidians (sea squirts) on the stainless mesh was observed. There was no distinct difference in the antifouling activity between the samples that were immersed at different depths in the sea $(5$ or $8 \mathrm{~m})$.

The fixation of gels within a stainless mesh is not a suitable option for testing in the marine environment because of the damage to the gel and the adhesion of sessile organisms to the mesh surface. Therefore, we tried a third method. In this method, samples were directly fixed with stainless frames without the stainless meshes (Figure 1c). Mechanically strong PVA and PAMPS/PAAm DN gels were used. The thickness of the gels was approximately $1 \mathrm{~cm}$. PVA gel $\left(10 \times 10 \mathrm{~cm}^{2}\right.$ in area) was opaque and PAMPS/PAAM DN gel $\left(12 \times 12 \mathrm{~cm}^{2}\right.$ in area $)$ was transparent. PE $(12 \times$ $12 \mathrm{~cm}^{2}$ in area) also served as a control. Samples were placed vertically at a depth of 5 $\mathrm{m}$ beneath the sea surface with nylon ropes from a raft. Data was collected by taking 2 specimens of every kind of gel.

PVA and PAMPS/PAAm DN gels were not broken for $330 \mathrm{~d}$ in marine environment. This test method permitted, for the first time, the long term observation using gels in marine environment. Figure 2 shows the top view photos of the samples after 71, 132, and 330 days of exposure. The photos were taken in air, after temporarily removing the sample from the sea. After 71 days, slight fouling of algae and barnacles was observed on the PE surface. The gel surfaces were visually clean; however, they were fouled with diatoms. After 132 days, the PE surface was fouled wall-to-wall by barnacles. In contrast, distinct inhibition of the settlement of the barnacles on both the PAMPS/PAAm DN and PVA gels was observed (many ascidians adhered to the 
stainless frame). Figure 3 shows the lateral view of the samples after 330 days. In Figure 3 , the substrate area was indicated by the dashed line. This figure shows that the large amount of barnacle adhered on PE surface compared to gels. The species of settled barnacles, which can be identified, are Megabalanus rosa, Fistulobalanus kondakovi, and Amphibalanus amphitrite, and the other sessile organisms are sponges, algae, and sea squirts.

After taking these pictures, the sessile organisms adhered on the surfaces were then collected under a wet environment. Figure 4 shows a gross dry weight of sessile organisms adhered to the surfaces. The composition of the barnacles and other sessile organisms were also shown in this figure. The fouling gross weight on gels were only $1 / 10 \sim 1 / 5$ of that on PE. Furthermore, on the PE substrate, the barnacle occupied the main portion $(77.5 \%)$ of the total weight, while on gel substrates, other sessile organisms occupied the main fouling weight. The dry weight of the barnacles on gels was only $7.7 \%$ (PVA gel) and 2.6\% (DN gel) of that on PE. On the other hand, the dry weight of the others sessile organisms were 58\% (PVA) and 32\% (DN gel) of that on PE. These results indicate that barnacles are much less fouling on gels.

Figure 5 shows photos of all of the barnacles collected from the two sides of each substrate in wet state. The figure shows that few barnacles adhered to PVA gel and PAMPS/PAAm DN gel, compared to PE. The area ratio of barnacles on the surface, which is estimated from the total barnacle bottom area to the gel (or PE) surface area, is shown in Figure 6 . The figure shows that the PE surface was almost completely covered with barnacles $(92.4 \%)$; however, only a small portion of the gel surface area was covered with barnacles (PVA, 7.4\% and PAMPS/PAAm DN, 3.3\%). The larger area ratio on $\mathrm{PE}$ than that on gels is caused by the higher number density of barnacle 
settlement and the larger size of individual barnacles on PE. The number density of barnacle settled on these surfaces was $0.98 \mathrm{~cm}^{-2}, 0.17 \mathrm{~cm}^{-2}$, and $0.11 \mathrm{~cm}^{-2}$, for PE, PVA gel, and PAMPS/PAAm DN gel, respectively, as shown in Figure 6.

Figure 7 shows the distribution of the bottom size of barnacles settled on each substrate. On PE, a peak in the size distribution was observed, and the average size was $10.4 \mathrm{~mm}$. On PAMPS/PAAm DN gel, the number of barnacles decreased as the size became larger, and the average size was $6.4 \mathrm{~mm}$. On PVA gel, the size distribution showed a shape between that of PE and PAMPS/PAAm DN gel, with an average size of $7.2 \mathrm{~mm}$. That is, on hydrogels, the number of barnacles was much less and the size was smaller than that on PE control. Since a larger diameter indicates an aged barnacle, the results in Figure 7 may be interpreted as follows. PE is a suitable substrate for barnacle settlement, and most of barnacles might not be detached from the surface once they settled. Thus, the right half of the histogram of PE (the number of barnacle increased with the decrease in size) means the initial settlement of barnacles have an effect of attraction on the subsequent settlement, in other words, the SIPC (settlement inducing protein complex) (Matsumura et al. 1998) of pioneers triggered new settlement. On the other hand, the left half of histogram (the number of barnacle decreased with the decrease in size) might be due to the decreasing of the available area for further settlement. Following this explanation, the smaller size and the monotonous decreasing in the barnacle number with the increase in its size on the DN gel can be understood as the "easy release" during the growth process, due to the weak adhesion of barnacles on the DN gels. The relatively abundant number of small size in DN might be due to the "easy release", which produce more unoccupied space, and the effect of attraction by SIPC of the previous settlement. The asymmetric peak observed on PVA gel in Figure 
7 suggests a less "easy release" than on DN gels. Small size may also means that the metabolic rate of barnacles on gel surfaces were slower than on solid surface. These possible mechanisms should be clarified by in-situ observation during the growing process in future studies.

Figure 8 shows images of the bottom surfaces of the barnacles settled on PE, PAMPS/PAAm DN gel, and PVA gel. The morphology of the barnacle bottom surface depends on the substrate on which it settled. A flat bottom surface was observed on hard $(E=151 \mathrm{MPa}) \mathrm{PE}$ substrate. On the other hand, a very rough and concave surface was observed on the soft $(E=0.09 \mathrm{MPa})$ PVA gel surface. On the PAMPS/PAAm DN gel, which was relatively rigid $(E=1.25 \mathrm{MPa})$ in comparison with PVA gel, a slightly concave surface was observed. The morphology changes did not depend on barnacle species. Our results are in agreement with the literature which reported that barnacle bottom was flat on rigid PMMA but showed a concave shape on relatively soft polydimethylsiloxane (PDMS) substrate (Berglin and Gatenholm 2003). It has been reported that on soft PDMS, larger amount of adhesive substance was observed at the interface. However, we could not distinguish directly the amount of adhesive substance from this study.

In a previous report, we found that acorn barnacles showed less settlement on "soft and wet" gels than on "hard and dry" solid in laboratory test (in vitro). Here we make a comparison between the results in vivo and in vitro. Figure 9 shows the results of settlement test in both laboratory (Murosaki et al. 2009) and marine environment as a function of the swelling degree $q$ of the substrate, in which $q$ is defined as the weight $\operatorname{ratio}(\mathrm{g} / \mathrm{g})$ of the gel in water swollen state to that in dried state. For the solid state material, $q=1$ since it does not adsorb water. The swelling ratio $q$ is related to the weight 
percentage of water content as $c(w t \%)=\left(1-q^{-1}\right) \times 100 \%$. This figure shows that PAMPS/PAAm DN and PVA gels exhibited high antifouling performance in both environments than that of solids (PE, PS).

Here, we discuss the mechanism of antifouling property of hydrogel. The high water content (85-90 wt\%) of the hydrogels is assumed to be the reason of low adhesion of sessile organisms. Figure 10 is schematic illustration of barnacle settlement adapted from (Saroyan et al. 1970). Figure 10 (a) shows the components of an adult barnacle from a lateral view. Barnacle's basis and shell wall are tightly fixed with muscle, and there are ducts, which lead to cement gland in between basis and shell wall. The growing process of adult barnacle on the solid surface is shown in Figure 10 (b). When adult barnacle secretes new cement to the surface, the muscles contract, so the basis is subjected to a pull-up force and the shell wall exerts a pressing force to the substrate. If the adhesive strength between basis and substrate is stronger than the pull-up force, new cement layer is built without detachment. This is the case on PE. However, if the adhesive strength between basis and substrate is weaker than the pull-up force, detachment occurs. This might be the case of gels. As schematically illustrated in Figure 10(c), on a gel surface, cement proteins secreted might not be able to form the cement layer, because hydrogels contain abundant amount of water (about $85-90 \mathrm{wt} \%$ ), and the cement proteins (14 - $165 \mathrm{kDa})$ (Kamino. 2008) of adult barnacles can diffuse easily into gel network $(>10 \mathrm{~nm})$. Therefore, the adhesion strength on gels might be lower than contractile force, and detachment occur with a high probability.

As shown in Figure 9, the settlement of acorn barnacles decreased with the increase in the degree of swelling (or water content) of the substrate in the laboratory test, and a lower settlement was observed on PVA gel than on PAMPS/PAAm DN gel. However, 
the barnacle density in the marine environment was opposite, that is, PVA showed a higher barnacle density on PVA gel than on PAMPS/PAAm DN gel. The difference is also observed in the barnacle size distribution as shown in Figure 7. On DN gel we observed a higher number in the settlement of the small young barnacles than that on PVA gel, while the number of large adult barnacles on PVA gel was higher than that on DN gel. This indicates that it is easier for settled barnacles to be detached during the growing process on DN gel than on PVA gel. Furthermore, we found that it was very difficult to detach the settled barnacle from PVA than from DN gels for the samples 330 days of exposure to the marine environment, indicating that the bonding strength of the barnacle on PVA gel was stronger than on the DN gel. We try to explain this phenomenon in terms of the elastic modulus of the substrate. In the growing process, detachment of barnacles from the surface not only depend on adhesion strength between basis and the substrate, but also on the elastic modulus of substrate. Figure 11 schematically illustrates the effect of these two factors on the growing process of barnacles. On PE plate, as previously mentioned, the adhesion strength is strong enough that the barnacle does not detached from the substrate during muscle contraction that persists in the adult form, and the substrate is not deformed by the contractile force because of the high elastic modulus of PE, as revealed by the flat morphology of bottom surface of barnacle on PE in Figure 8.

On PAMPS/PAAm DN gel, the concave shaped bottom surface of barnacles (Figure 8) indicates that DN gel deformed by shell wall pushing during the growing process of barnacle. Since the adhesion strength is weak because of the abundant amount of water contained in the gel, the barnacle is easily detached from the DN gel when the a bending deformation is exerted on the gel, 
As shown in Figure 8, on PVA gel, the shell wall of barnacle embedded into PVA gel, due to the soft nature of PVA gel (elastic modulus $E=0.09 \mathrm{MPa}$ ), compared to PE (151 MPa) and PAMPS/PAAm DN (1.51 MPa). Therefore, shell wall can break PVA gel and embedded into PVA gel during muscles contraction. The adhesion strength on PVA gel might be as weak as on PAMPS/PAAm DN gel, however, this embedding of the shell wall might result in a mechanical locking of the shell wall to the PVA gel, which leads to less "easy release" of barnacles on PVA than on PAMPS/PAAm DN gel. Thus, we observed a higher number of barnacle settlement on PVA gel than that on PAMPS/PAAm DN gel in the long term test.

According to the above discussion, the water content and elastic modulus of hydrogels might be two significant factors for the "easy-release" behavior of barnacle from a substrate. In the initial settlement stage, adhesion strength of adult barnacle is important. Most of settled barnacle might be removed from gel surfaces in initial settlement stage due to the weak adhesion strength that is depend on water content. In the matured stage, the "easy-release" activity of gels depends on the elastic modulus of gel. When the gel is relatively rigid, barnacle is easily detached off by muscle contraction. When the gel is so soft that the shell wall is able to embed into the gel, then, this detachment occurs less frequently and therefore more barnacles remain on the substrate even if the adhesion is weak.

An empirical relationship between critical surface tension of several substrates and retention strength of adhered biofouling organisms has been reported (Baier 2006). The report shows that the retention strength of adhered biofouling organisms is in minimum on the surfaces having the critical surface tension value between 20 and $30 \mathrm{mN} / \mathrm{m}$, and after reaching a peak at $60 \mathrm{mN} / \mathrm{m}$, it drastically decreases again with the increase in the 
critical surface tension. For example, PDMS with a critical surface tension of 20-30 $\mathrm{mN} / \mathrm{m}$ exhibits less fouling (Brady et al. 1987), while other solids with a critical surface tension out of the "minimal fouling" range, such as Teflon $(18.5 \mathrm{mN} / \mathrm{m})$, PE $(33.5 \mathrm{mN} / \mathrm{m})$ and PVC $(39 \mathrm{mN} / \mathrm{m})$ (Ishii. 2001), show high fouling. The critical surface tension of water is about $22 \mathrm{mN} / \mathrm{m}$ (Zisman. 1967). Since a hydrogel usually contains more than $80 \mathrm{wt} \%$ of water (for example, $90 \mathrm{wt} \%$ for PVA and $85 \mathrm{wt} \%$ of DN in the present study), the critical surface tension of hydrogels might be almost the same as water. So the behavior of hydrogel also follows this empirical relation between the fouling and the critical surface tension.

\section{Conclusions}

The marine environment test was successfully performed on gels for as long as $330 \mathrm{~d}$, and for the first time, the PVA and DN gels were observed to have an antifouling effect against barnacles. We also evaluated the antifouling activity of agarose, $\kappa$-carrageenan, PAAm, PAMPS, PAAc, PAMPS/PAAm/PAMPS TN, and PAAc/PAAm/PAAc TN; they were found to be mechanically durable for 2 months in marine environment. Thus, we assume that these gels might also show long term antifouling activity if they are mechanically tough enough, because of some of these gels show antifouling activity in vitro.

The high antifouling activity of a hydrogel is originated from its high water content, which prevents the cement proteins to form bridge between the basis of barnacles and the gel substrate. Besides, the elasticity of the gel may also play a role in the detachment of the barnacles form the substrate. For a very soft gel, even if the adhesion is low, 
mechanical inter-locking of the shell wall of the barnacles to the gel may favor the settlement.

These results demonstrate that hydrogels have the high potential as excellent candidates for an environmental-benign antifouling system, because the antifouling performance is an intrinsic feature of gels due to their soft and wet nature. Therefore, gel coating for fishnet, ship's bottom, and pipelines might be very useful to prevent barnacle's fouling. Furthermore, increasing of fuel economy of ship is also expected due to fascinatingly low friction of hydrogel.

\section{Acknowledgments}

This research was financially supported by a Grant-in-Aid for seeds innovation project from Science and Technology, Japan, and the Specially Promoted Research (No. 18002002) from the Ministry of Education, Science, Sports and Culture of Japan. 


\section{References}

Baier RE. 2006. Surface behaviour of biomaterials: The theta surface for biocompatibility. J Mater Sci: Mater Med. 17:1057-1062.

Berglin M, Gatenholm P. 2003. The barnacle adhesive plaque: morphological and chemical differences as a response to substrate properties. Colloids and Surfaces B: Biointerfaces. 28: 107-117.

Brady RF Jr, Griffith JR, Love KS, Field DE. 1987. Nontoxic alternatives to antifouling paints. J Coatings Technol. 59:113-119.

Chambers LD, Stokes KR, Walsh FC, Wood RJK. 2006. Modern approaches to marine antifouling coatings. Surface \& Coatings Technology. 201:3642 - 3652

Chen YM, Shiraishi N, Satokawa H, Kakugo A, Narita T, Gong JP, Osada Y, Yamamoto K, Ando J. 2005. Cultivation of endothelial cells on adhesive protein-free synthetic polymer gels. Biomaterials. 26:4588-4596.

Cowling MJ, Hodgkiess T, Parr ACS, Smith MJ, Marrs SJ. 2000. An alternative approach to antifouling based on analogues of natural processes. Sci Tot Env. 258:129-137.

Gong JP, Katsuyama Y, Kurokawa T, Osada Y. 2003. Double-Network Hydrogels with Extremely High Mechanical Strength. Adv Mater. 15:1155-1158.

Gong JP, 2006. Friction and lubrication of hydrogels - its richness and complexity. Soft Matter. 7:544-552.

Ishii T. 2001. The wettability of plastic materials. In: The handbook for the technology of wettability. Tokyo: Technosystem, Inc. pp. 149-218.

Kagata G, Gong JP, Osada Y. 2002. Friction of Gels. 6. Effects of Sliding Velocity and Viscoelastic Responses of the Network. J Phys Chem B. 106:4596-4601. 
Kamino K. 2008. Underwater Adhesive of Marine Organisms as the Vital Link Between Biological Science and Material Science. Mar Biotechnol. 10:111-121. Matsumura K, Nagano M, Kato-Yoshinaga Y, Yamazaki M, Clare AS, Fusetani N. 1998. Immunological studies on the settlement-inducing protein complex (SIPC) of the barnacle Balanus amphitrite and its possible involvement in larva-larva interactions. Proc. R. Soc. Lond. B. 265: 1825-1830.

Murosaki T, Noguchi T, Kakugo A, Putra A, Kurokawa T, Furukawa H, Osada Y, Gong JP, Nogata Y, Matsumura K, Yoshimura E, Fusetani N. 2009. Antifouling activity of synthetic polymer gels against cyprids of the barnacle (Balanus amphitrite) in vitro. Biofouling. 25:313-320.

Saroyan JR, Lindner E, Dooley CA. 1970. Repair and Reattachment in the Balanidae as Related to Their Cementing Mechanism. Biol. Bull. 139:333-350.

Shafrin EG, Zisman WA. 1967. Critical surface tension for spreading on a liquid substrate. J Phys Chem. 71:1309-1316. 


\section{Figure captions}

Figure 1. 3 methods used to fix the gel samples. (a) thin gel films coated on PE plates and the PE plates were fixed to stainless frames; (b) bulk gels were sandwiched between two stainless meshes; and (c) mechanically tough PVA and PAMPS/PAAm DN gel bulk were directly fixed by the stainless frames without the stainless meshes. The areas of gels were $100 \mathrm{~cm}^{2}, 50-100 \mathrm{~cm}^{2}$, and $100-144 \mathrm{~cm}^{2}$, in the case of (a), (b), and (c), respectively.

Figure 2. The surface conditions of polyethylene(PE) (left), PVA gel (center), and PAMPS/PAAm DN gel (right) before and after 71, 132, and $330 \mathrm{~d}$ of exposure to the marine environment. The red square corresponds to the same position of the test sample. The surface of polyethylene and stainless frames were fouled with barnacles (shows in the white circle) and ascidians (sea squirt, showed in the dashed white circle).

Figure 3. Photographs of substrates with fouling after $330 \mathrm{~d}$ of exposure to the marine environment. The photographs were taken from the lateral view of the substrates. The red dashed lines correspond to the area of the substrate.

Figure 4. Gross dry weight of sessile organisms settled on surfaces after $330 \mathrm{~d}$ of exposure.

Figure 5. A photograph of the total amount of barnacles settled on the two sides of surfaces of PE and the gel plates after $330 \mathrm{~d}$ of exposure.

Figure 6. Area ratio and the density of barnacles settled on various surfaces after $330 \mathrm{~d}$ of exposure.

Figure 7. Bottom diameter distribution of barnacle settled on various surfaces, after 330 $d$ of exposure. The average diameter of PE, PAMPS/PAAm DN gel, and PVA gel were $10.4 \mathrm{~mm}, 6.4 \mathrm{~mm}$, and $7.2 \mathrm{~mm}$ respectively. 
Figure 8. Photographs of the bottom surface morphology of barnacles settled on various surfaces, and the cross section illustrations of barnacles settled on each surfaces. Numbers in the parenthesis are the corresponding swelling degree $q$ of the substrate.

Figure 9. Relationship between degree of swelling of gel $q$ and relative number of settled barnacles in laboratory test or barnacle density in marine test.

Figure 10. Illustration of the growing process of adult barnacle adapted from (Saroyan et al. 1970). (a) components of adult barnacle, (b) growing process on solid surface, (c) growing and detachment process on gel surface.

Figure 11. Illustration of the growing process of a barnacle on substrates with difference elasticity.

Table 1. Results of field test for the second experiment. Abundance of barnacles on the surface of various gels and solid plates, and the degree of damage of samples after $42,71,88$, and $157 \mathrm{~d}$ of exposure to the marine environment were indicated.

${ }^{1}$ The days of exposure in sea.

${ }^{2}$ The degree of damage of samples: "present", without remarkable damage; "partially broken", a part of the sample was broken; "mostly broken", the most part of the sample was broken; "disappeared", whole sample did not exist due to complete damage ${ }^{3}$ Abundance of barnacles: +++, wall to wall covered; ++, covered over 50\%; +, present; -, no settlement; ND, not detectable 


\begin{abstract}
In marine environment, antifouling properties against marine sessile organisms (algae, sea squirts, barnacles, etc.) were tested on various kinds of hydrogels in a long term. The results demonstrate that most hydrogels can ensure at least 2 months in marine environment. In particular, mechanically tough PAMPS/PAAm DN and PVA gels exhibited amazing antifouling activity against marine sessile organisms, especially barnacles as long as 330 days. The antifouling ability of hydrogel to barnacle is explained in terms of "easy-release" mechanism in which the high water content and the elastic modulus of the gel are two important parameters.
\end{abstract}




\begin{tabular}{|c|c|c|c|c|c|c|c|c|}
\hline & \multicolumn{2}{|c|}{42 days $^{1}$} & \multicolumn{2}{|c|}{71 days } & \multicolumn{2}{|c|}{88 days } & \multicolumn{2}{|c|}{157 days } \\
\hline Samples & $\begin{array}{c}\text { Sample } \\
\text { condition } \\
2\end{array}$ & Barnacles $^{3}$ & $\begin{array}{l}\text { Sample } \\
\text { condition }\end{array}$ & Barnacles & $\begin{array}{c}\text { Sample } \\
\text { conditio } \\
n\end{array}$ & Barnacles & $\begin{array}{c}\text { Sample } \\
\text { conditio } \\
n\end{array}$ & Barnacles \\
\hline Agarose & present & - & present & - & $\begin{array}{l}\text { disappe } \\
\text { ared }\end{array}$ & ND & $\begin{array}{l}\text { disappe } \\
\text { ared }\end{array}$ & ND \\
\hline к-Carrageenan & present & - & present & - & $\begin{array}{l}\text { disappe } \\
\text { ared }\end{array}$ & ND & $\begin{array}{c}\text { disappe } \\
\text { ared }\end{array}$ & ND \\
\hline PAAm & $\begin{array}{l}\text { partially } \\
\text { broken }\end{array}$ & - & $\begin{array}{l}\text { mostly } \\
\text { broken }\end{array}$ & - & $\begin{array}{l}\text { disappe } \\
\text { ared }\end{array}$ & ND & $\begin{array}{c}\text { disappe } \\
\text { ared }\end{array}$ & ND \\
\hline PAMPS & present & - & present & - & $\begin{array}{l}\text { disappe } \\
\text { ared }\end{array}$ & ND & $\begin{array}{c}\text { disappe } \\
\text { ared }\end{array}$ & ND \\
\hline PAAC & present & - & $\begin{array}{l}\text { mostly } \\
\text { broken }\end{array}$ & - & $\begin{array}{l}\text { disappe } \\
\text { ared }\end{array}$ & ND & $\begin{array}{c}\text { disappe } \\
\text { ared }\end{array}$ & ND \\
\hline $\begin{array}{c}\text { PAMPS/PAAm } \\
\text { DN }\end{array}$ & present & - & present & - & present & - & present & + \\
\hline $\begin{array}{c}\text { PAAc/PAAm } \\
\text { DN }\end{array}$ & $\begin{array}{l}\text { partially } \\
\text { broken }\end{array}$ & - & $\begin{array}{l}\text { partially } \\
\text { broken }\end{array}$ & - & $\begin{array}{l}\text { partially } \\
\text { broken }\end{array}$ & - & $\begin{array}{c}\text { disappe } \\
\text { ared }\end{array}$ & ND \\
\hline $\begin{array}{c}\text { PAMPS/ } \\
\text { PAAm/PAMPS } \\
\text { TN }\end{array}$ & present & - & present & - & present & - & $\begin{array}{c}\text { disappe } \\
\text { ared }\end{array}$ & ND \\
\hline $\begin{array}{l}\text { PAAc/PAAm/ } \\
\text { PAAc TN }\end{array}$ & $\begin{array}{l}\text { partially } \\
\text { broken }\end{array}$ & - & $\begin{array}{l}\text { partially } \\
\text { broken }\end{array}$ & - & $\begin{array}{l}\text { mostly } \\
\text { broken }\end{array}$ & - & $\begin{array}{l}\text { disappe } \\
\text { ared }\end{array}$ & ND \\
\hline $\begin{array}{l}\text { Poly vinyl } \\
\text { chloride }\end{array}$ & present & + & present & + & present & ++ & present & +++ \\
\hline Teflon & present & + & present & + & present & ++ & present & +++ \\
\hline
\end{tabular}


(a)

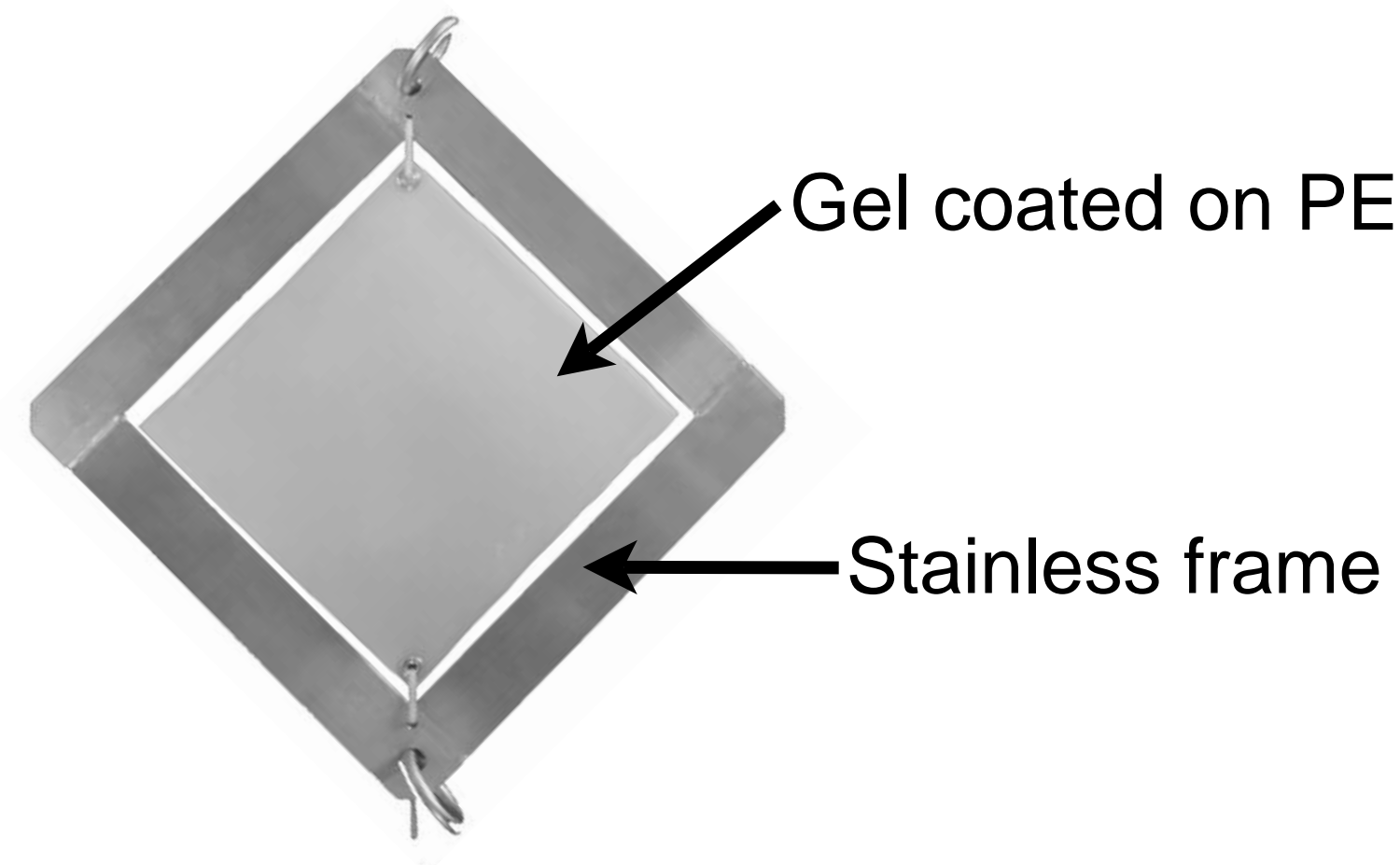

(b)

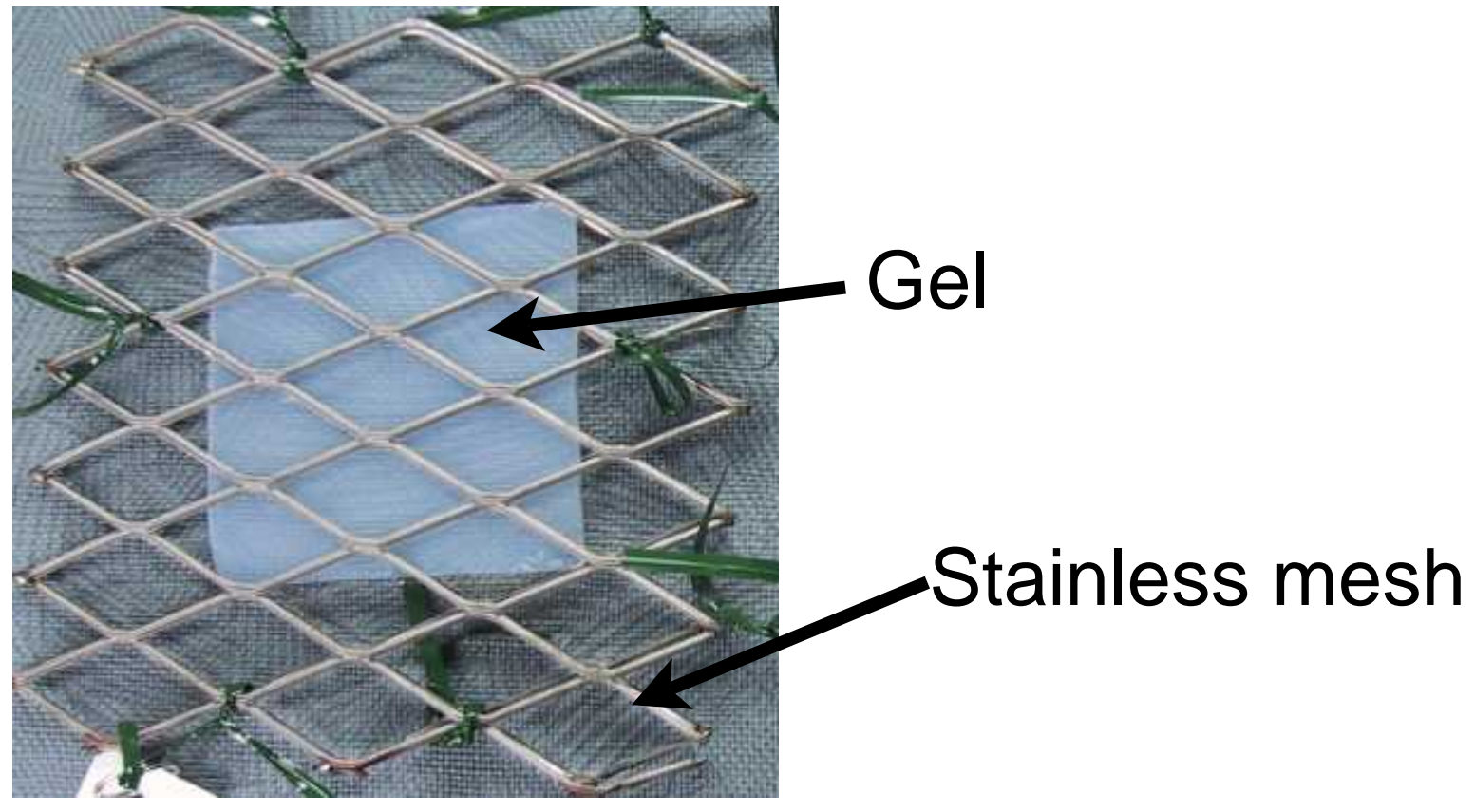

(c)

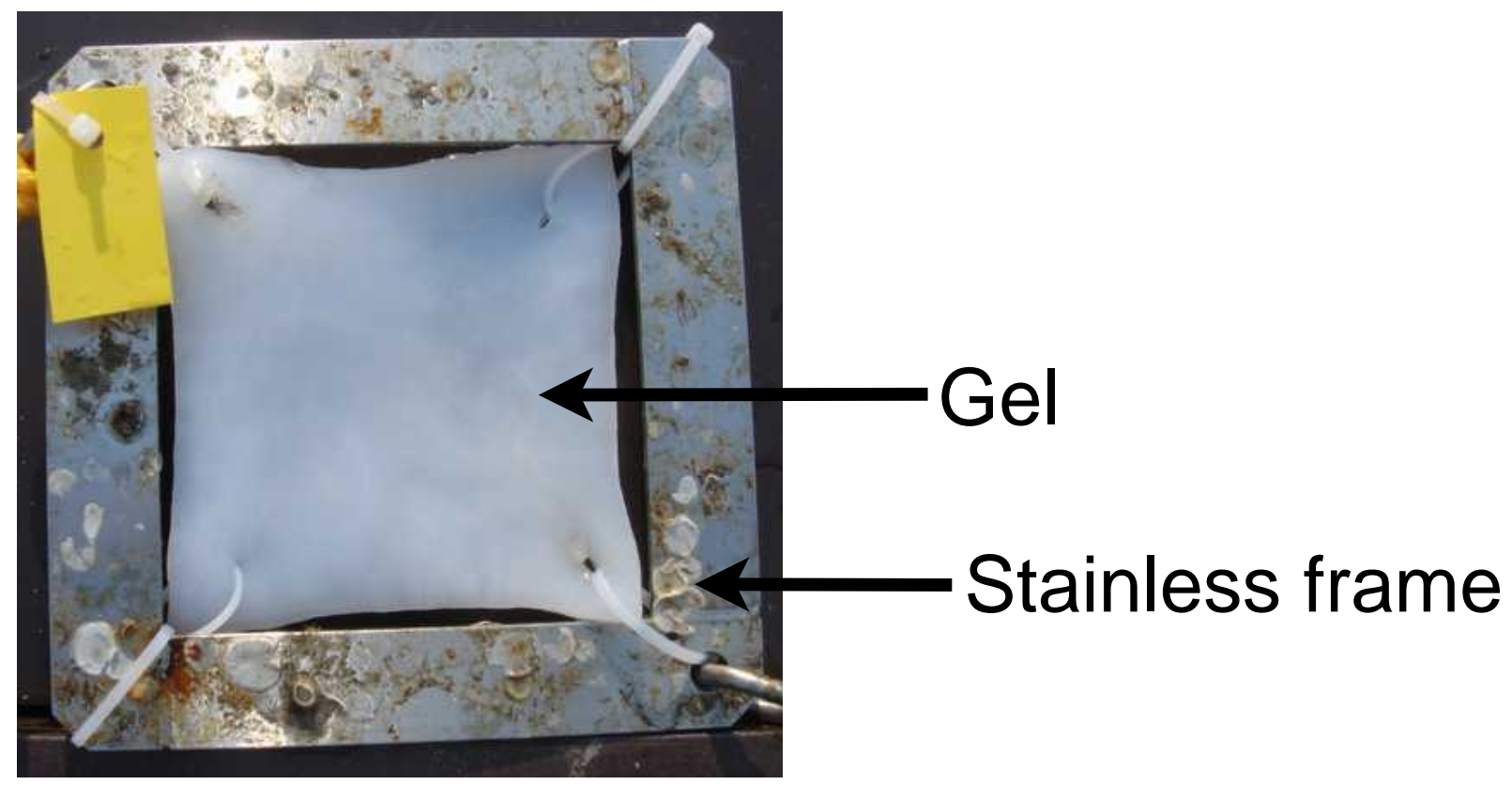

Figure 1. 


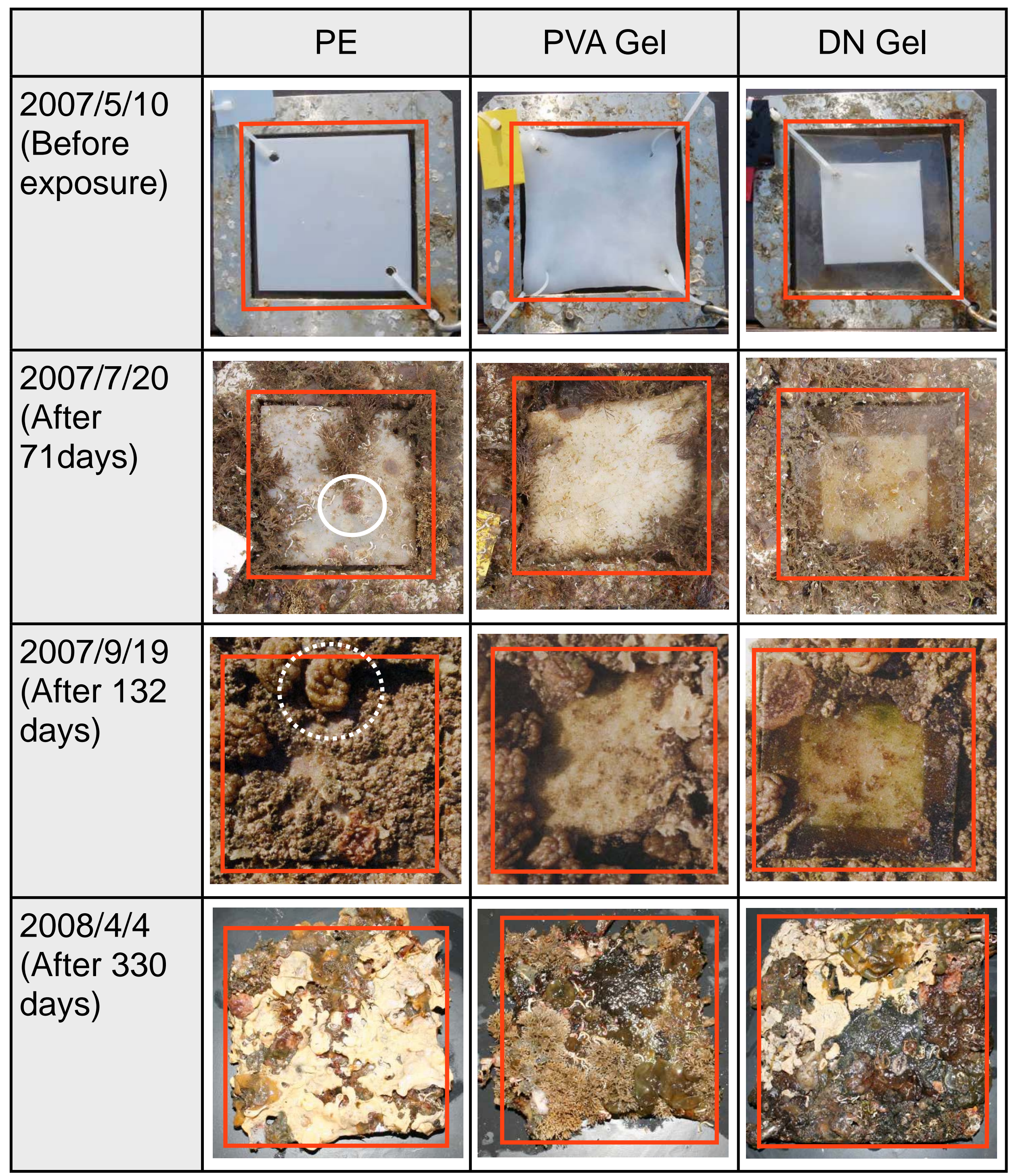



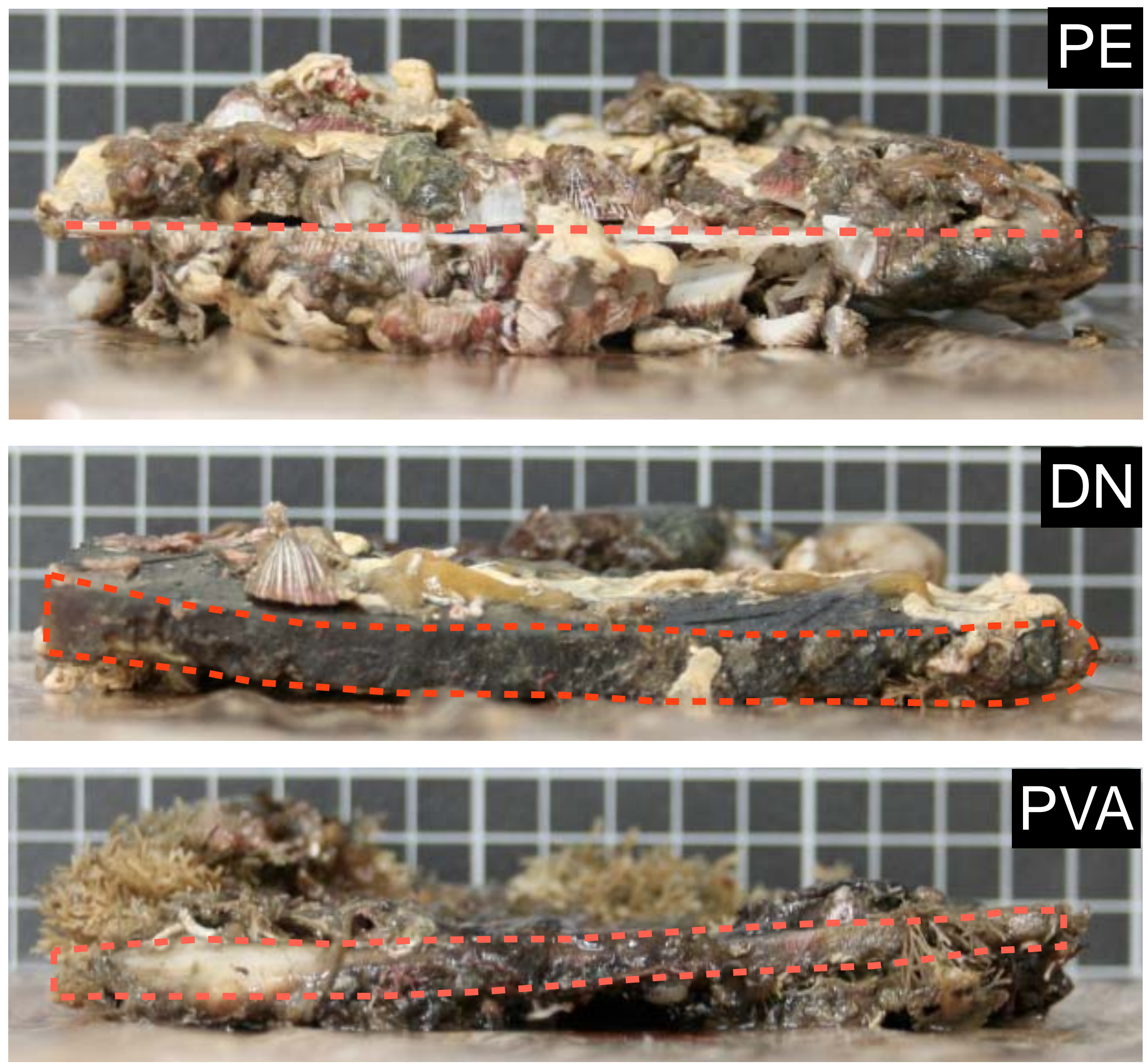

Figure 3. 


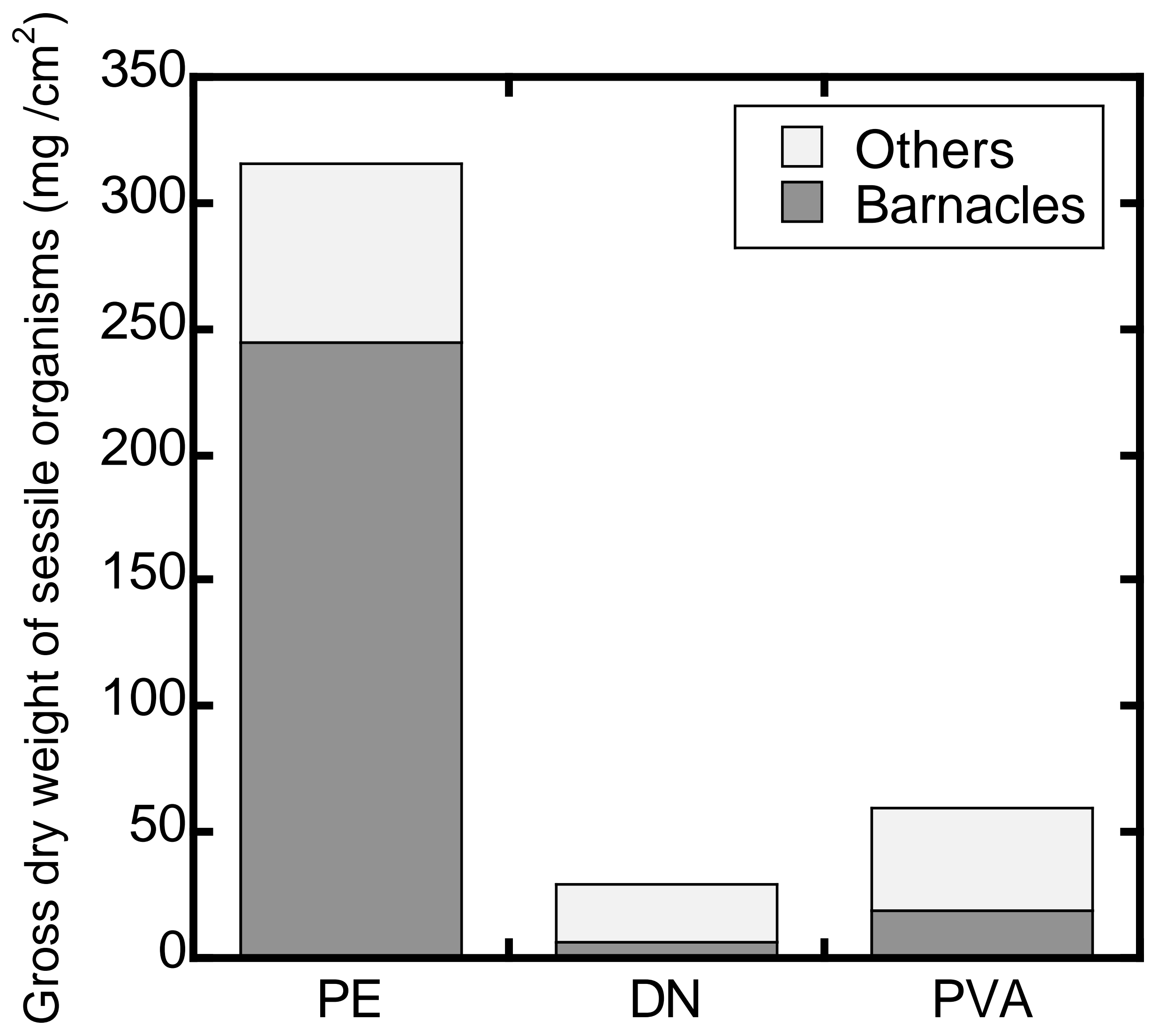

Figure 4. 


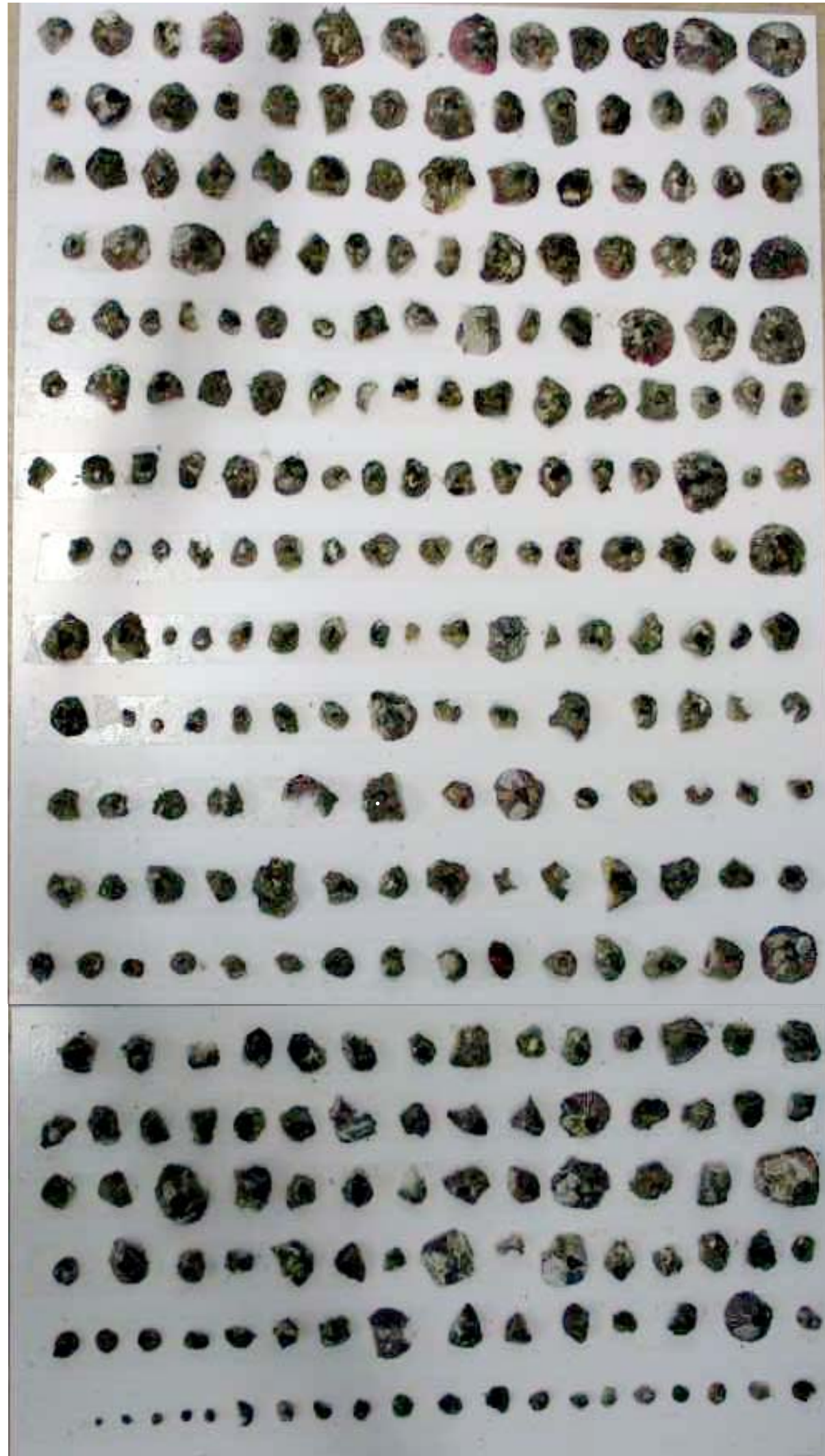

$4 \mathrm{~cm}$

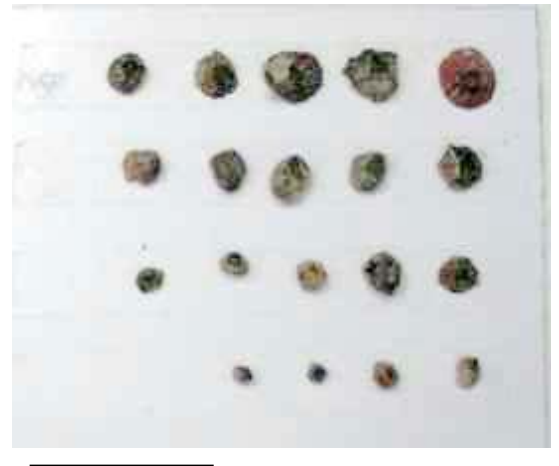

$\overline{4 \mathrm{~cm}}$

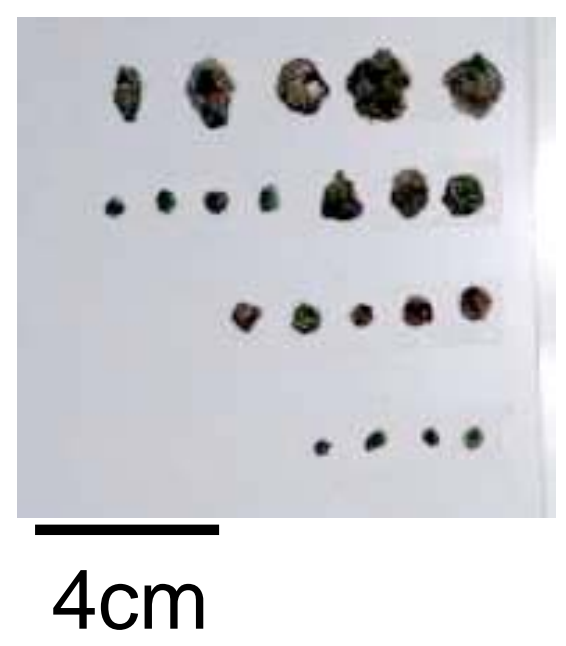

PVA Gel

\section{PE}

DN Gel 


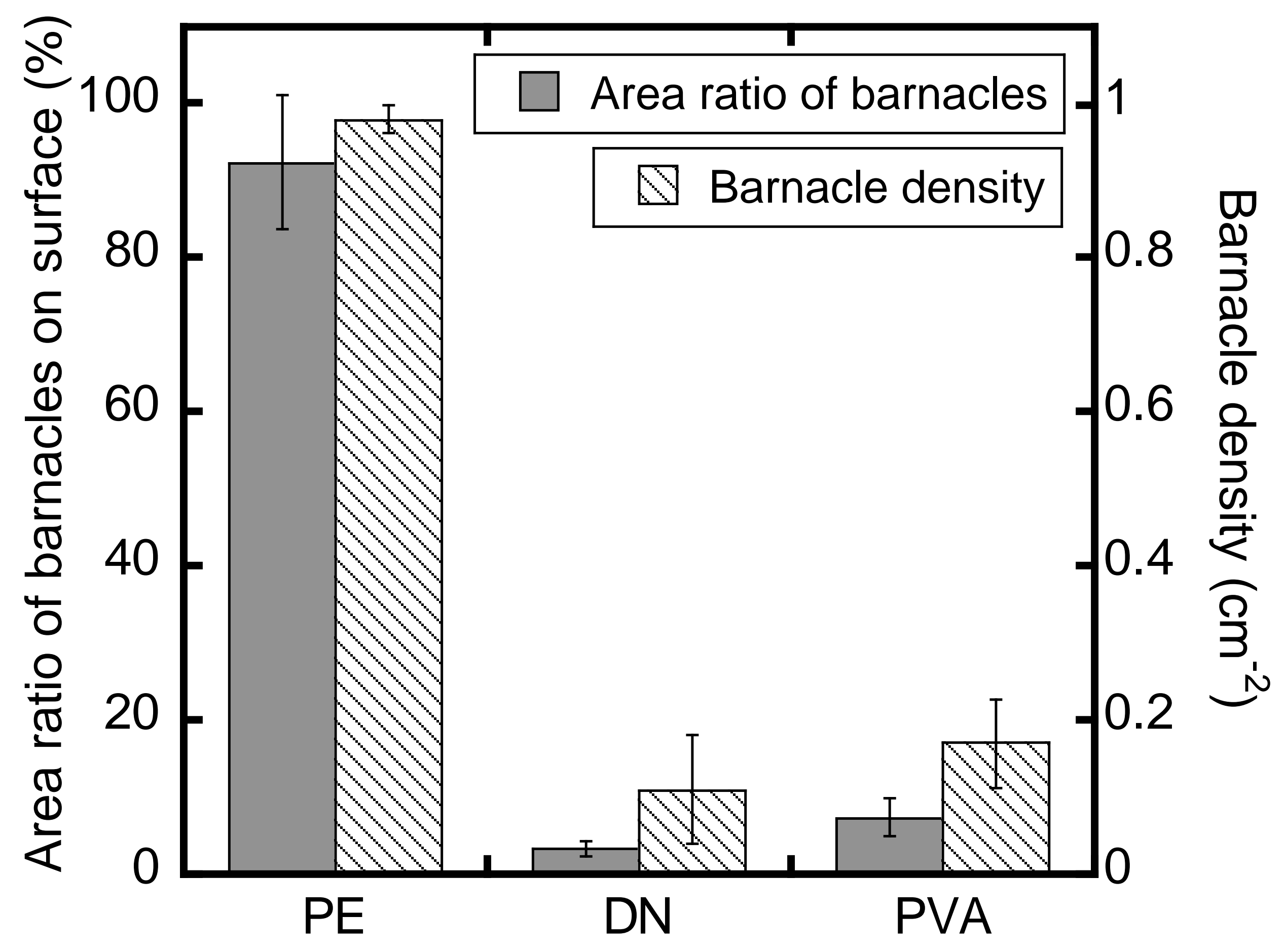

Figure 6. 

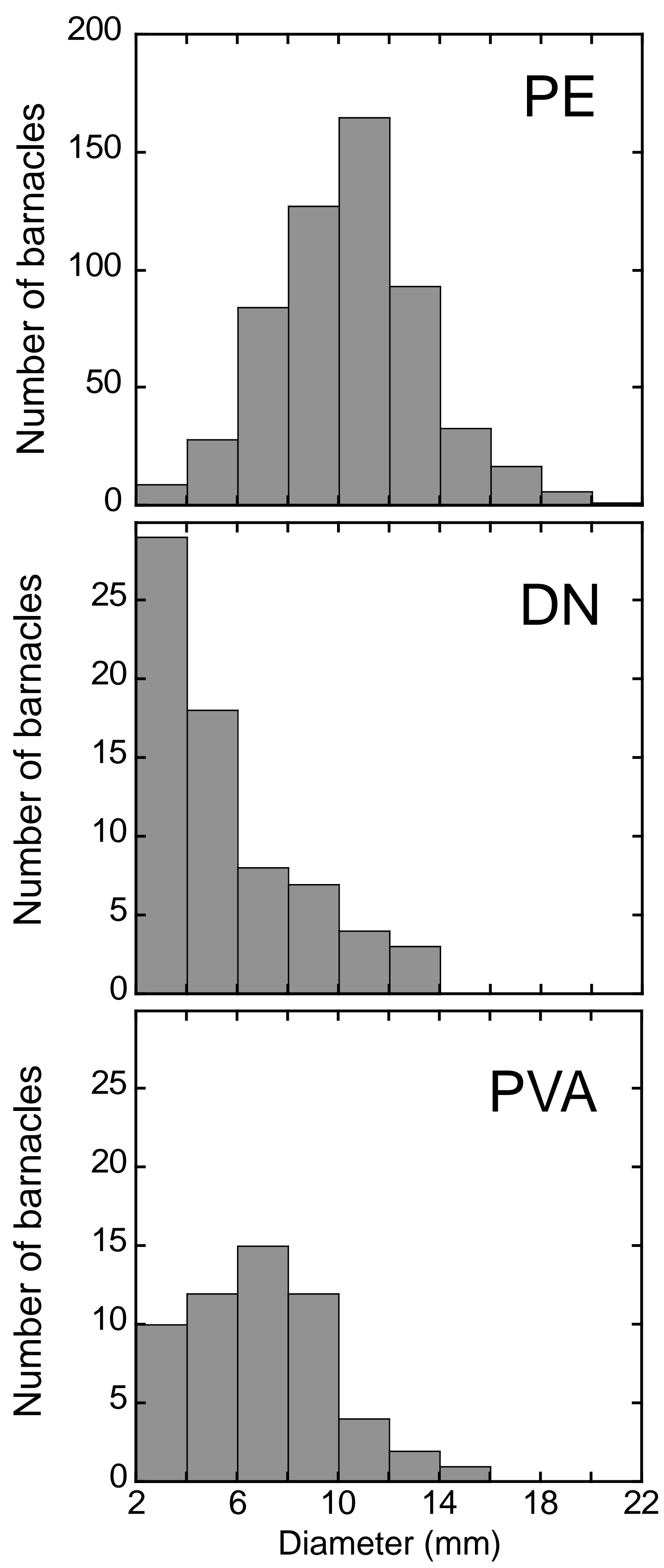

Figure7. 


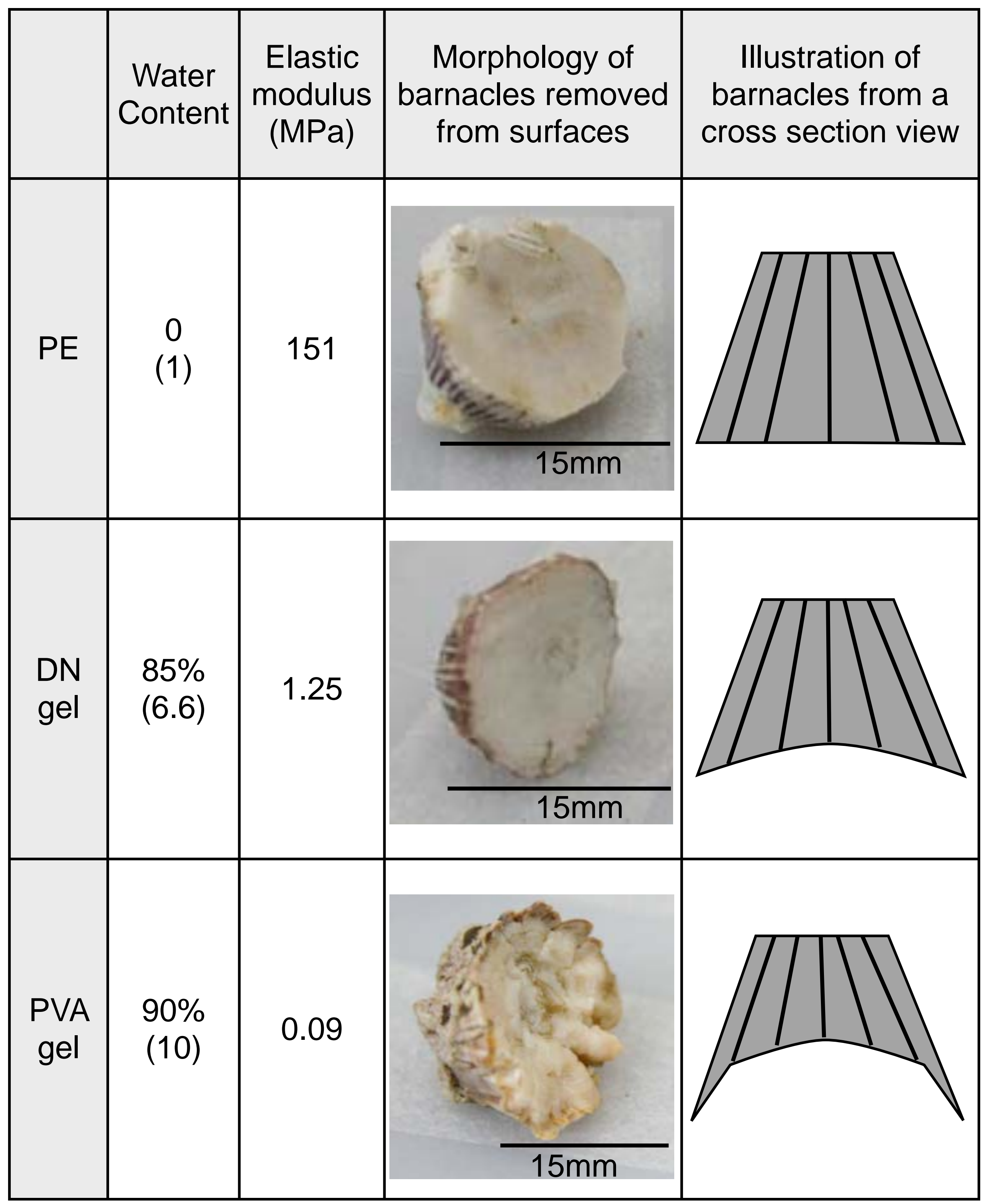

Figure 8. 


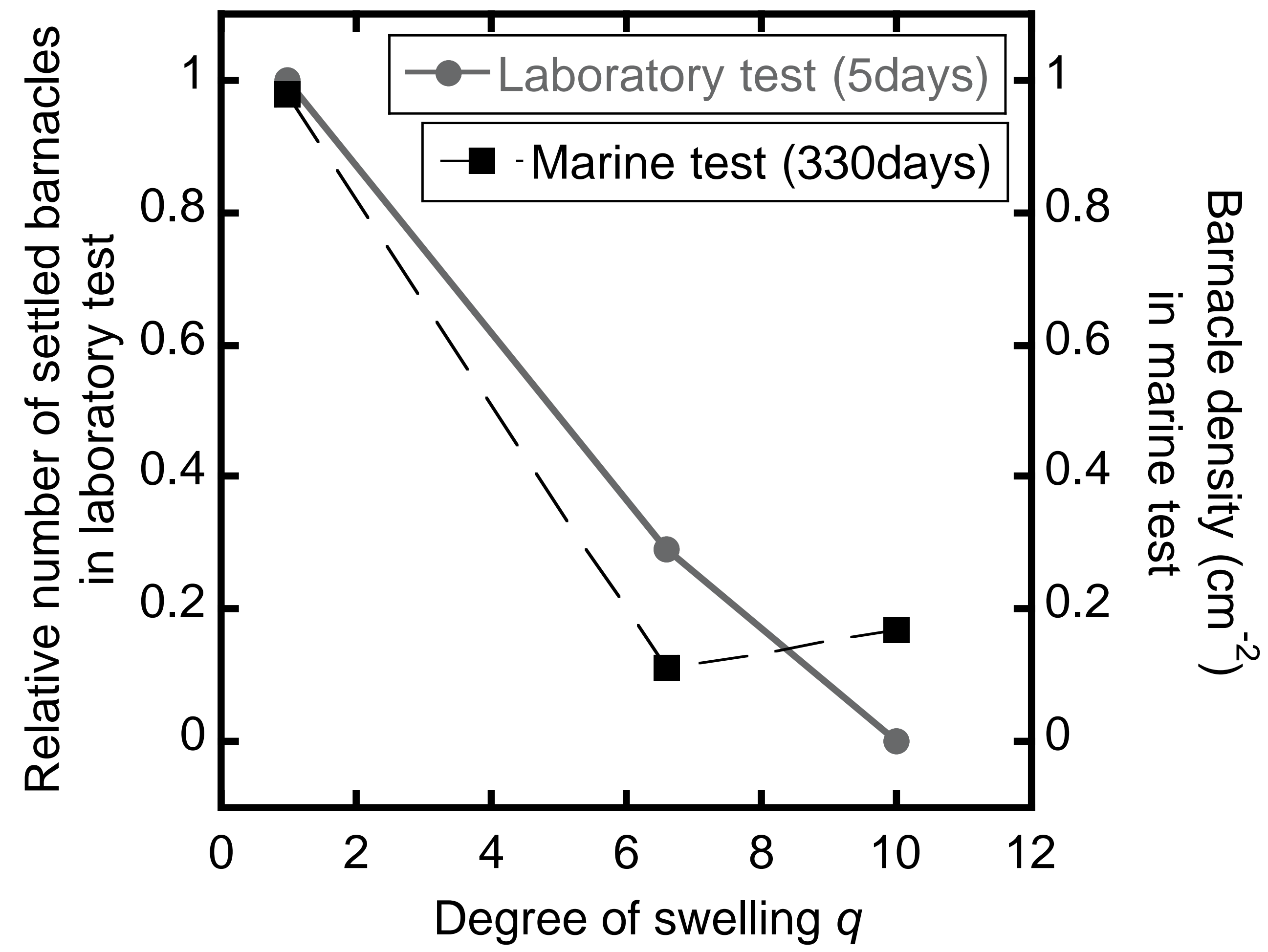

Figure 9. 
(a)

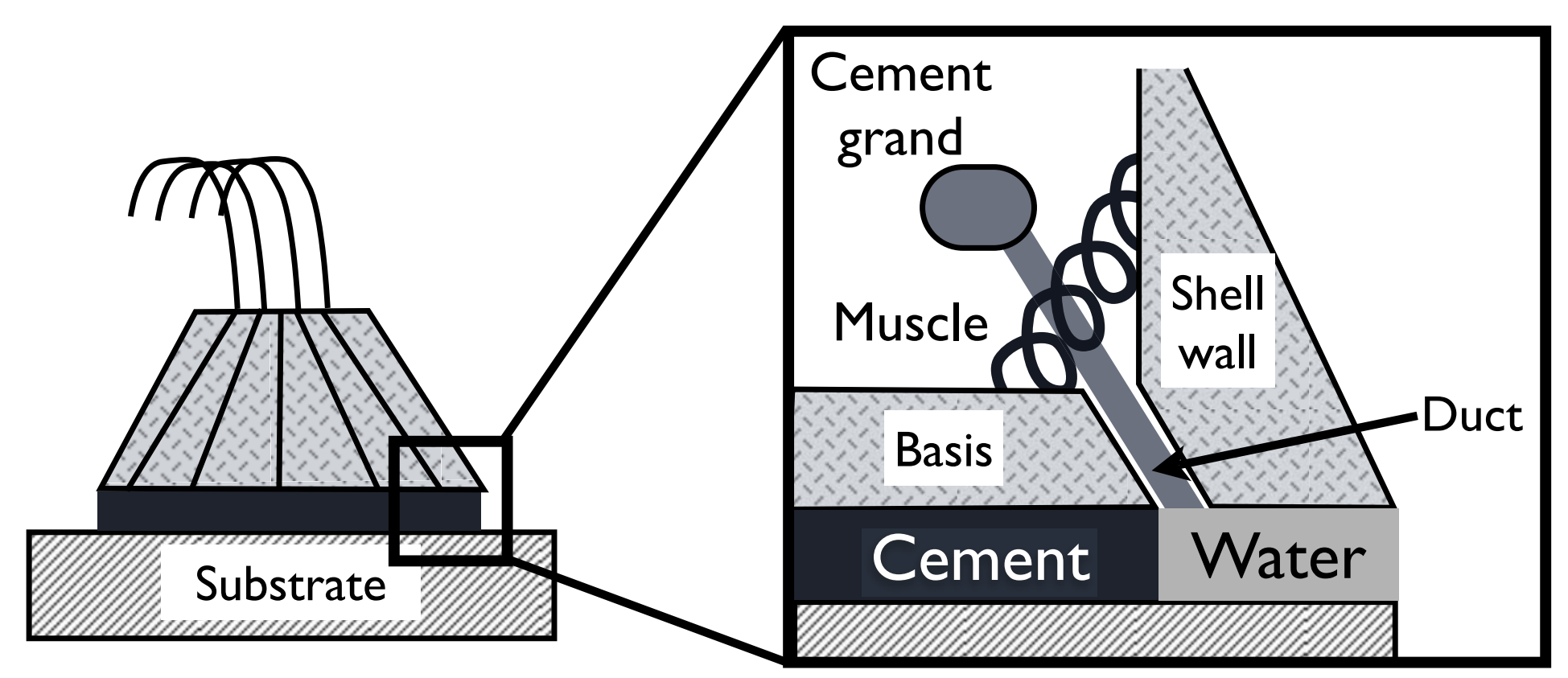

(b)

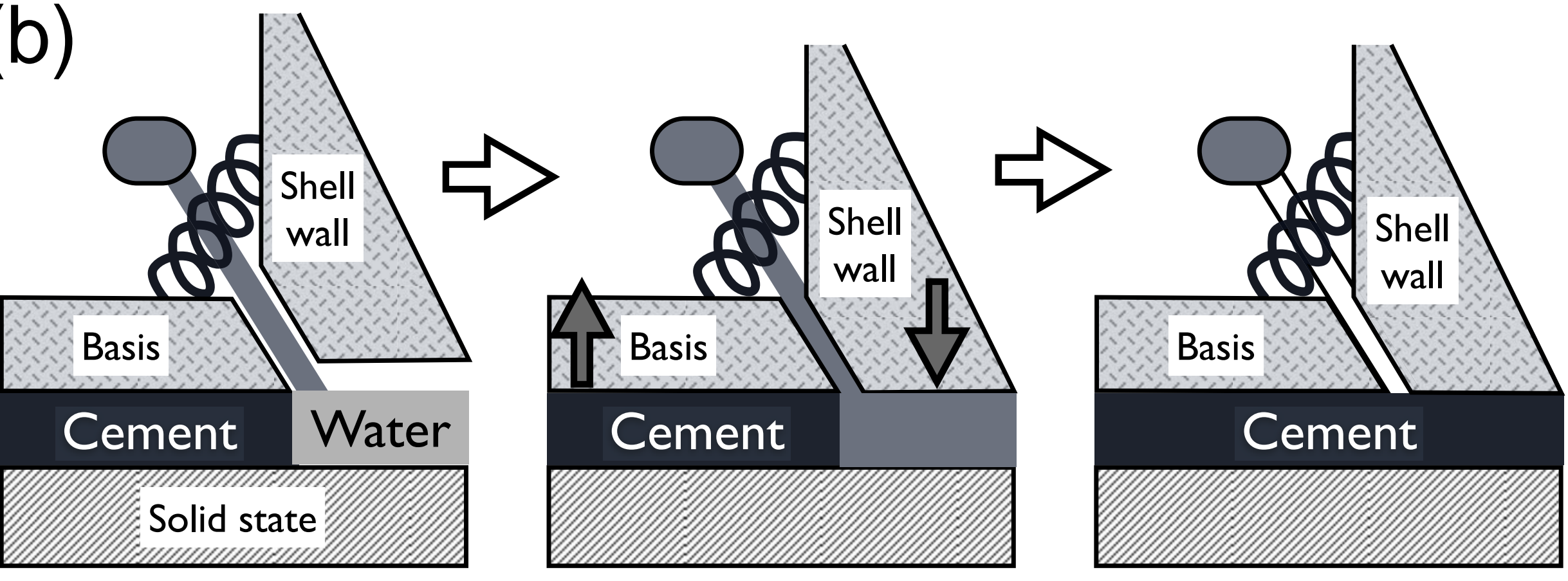

(c)

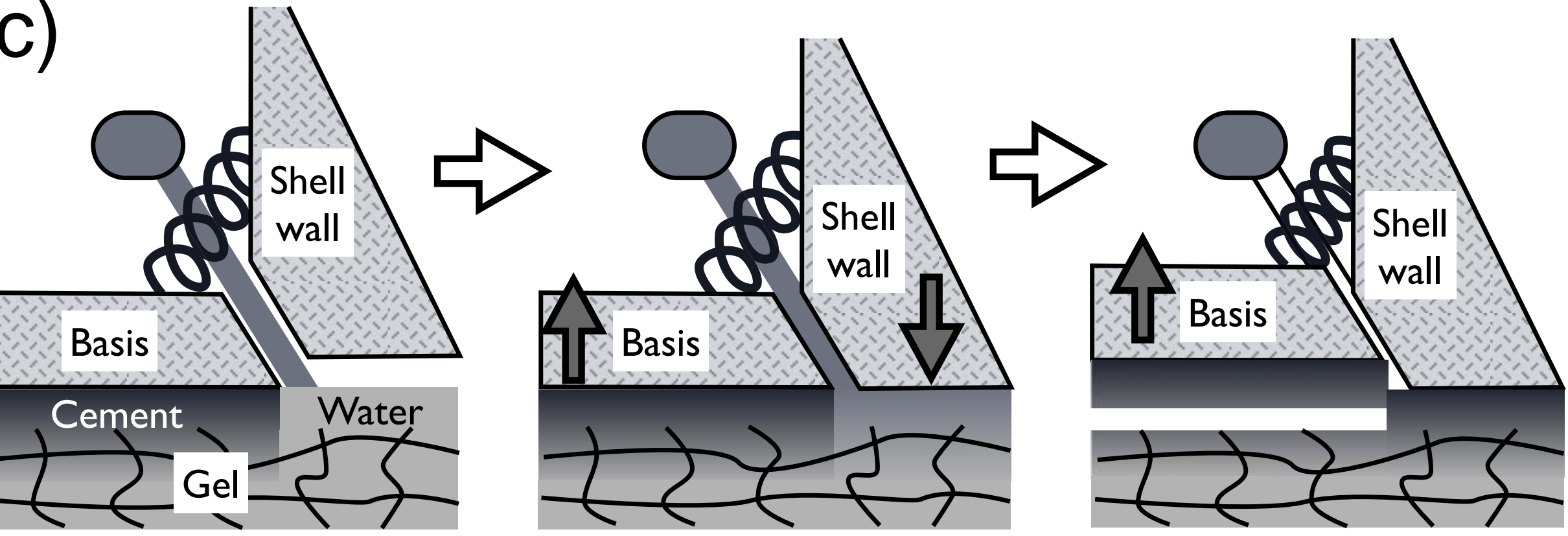

Figure 10. 
